Int. J. Electrochem. Sci., 11 (2016) 10053 - 10066

\title{
Corrosion Behavior of Electroless Ni-P/Ni-B Coating on Magnesium Alloy AZ91D in NaCl Environment
}

\author{
Jun Zhang ${ }^{1}$, Zhengwei Song ${ }^{2, *}$, Gang $\mathrm{Yu}^{1,{ }^{*}}$, Bonian $\mathrm{Hu}^{3}$, Xueyuan Zhang ${ }^{1}$ \\ ${ }^{1}$ State Key Laboratory of Chemo/Biosensing and Chemo metrics, College of Chemistry and Chemical \\ Engineering, Hunan University, Changsha 410082, PR China \\ ${ }^{2}$ Department of Chemistry and Chemical Engineering,Taiyuan Institute of Technology, Taiyuan \\ 030024, PRChina \\ ${ }^{3}$ Department of Materials and Chemical Engineering, Hunan Institute of Technology, Hengyang \\ 421002, PR China \\ *E-mail: adsszw@163.com, yuganghnu@163.com
}

doi: $10.20964 / 2016.12 .57$

Received: 27 August 2016 / Accepted: 13 October 2016 / Published: 10 November 2016

The Ni-P/Ni-B coating was deposited on AZ91D magnesium alloy by electroless plating. Ni-P coating as inner layer and $\mathrm{Ni}-\mathrm{B}$ coating as outer layer. A tight and compact $\mathrm{Ni}-\mathrm{P} / \mathrm{Ni}-\mathrm{B}$ coating on $\mathrm{Mg}$ alloy substrate was formed via Ni-P plating for $70 \mathrm{~min}$ and $\mathrm{Ni}-\mathrm{B}$ plating for $20 \mathrm{~min}$. The corrosion behavior of coating was studied by electrochemical test and neutral salt spray test in the presence of chloride environment. The test results shown that the double coating has better corrosion resistance than single $\mathrm{Ni}-\mathrm{P}$ or Ni-B coating. Ni-B plated outer layer functions as cathodic protective and sealing layer, assisting Ni-P coatings in obstructing the attack of $\mathrm{Cl}^{-}$in the stage of long-term immersion in $\mathrm{NaCl}$ solution.

Keywords: Electroless Ni-P; Electroless Ni-B; Corrosion; Mg alloy; EIS

\section{FULL TEXT}

(C) 2016 The Authors. Published by ESG (www.electrochemsci.org). This article is an open access article distributed under the terms and conditions of the Creative Commons Attribution license (http://creativecommons.org/licenses/by/4.0/). 